\title{
Single or Combined Valve Surgery and Concomitant Right Coronary Artery Bypass through Right Anterior Minithoracotomy Approach
}

\author{
Ali Ihsan Hasde ${ }^{1}$ Mehmet Cahit Sarıcaoğlu ${ }^{1}$ Mustafa Kılıçkap ${ }^{2}$ Mustafa Serkan Durdu ${ }^{1}$ \\ 1 Department of Cardiovascular Surgery, Heart Center, Ankara \\ Address for correspondence Mustafa Serkan Durdu, Department of \\ University School of Medicine, Ankara, Turkey \\ 2 Department of Cardiology, Heart Center, Ankara University School \\ of Medicine, Ankara, Turkey \\ Cardiovascular Surgery, Heart Center, Ankara University School of \\ Medicine, Dikimevi, Ankara 06340, Turkey \\ (e-mail: serkandurdu@gmail.com).
}

Thorac Cardiovasc Surg

\begin{abstract}
Background Patients with combined valve and coronary artery disease are commonly performed by standard median sternotomy approach for coronary artery bypass grafting ( $C A B G$ ) and valve surgery. The purpose of this study is to describe our experience and show feasibility and safety of minimally invasive approach to single or combined valve pathology with single-vessel right coronary artery (RCA) disease, even if it is suitable to percutaneous coronary intervention.

Methods This retrospective study comprised 28 consecutive patients who underwent single or combined valve surgery concomitant right CABG through right anterior minithoracotomy between February 2018 and December 2020. Preoperative evaluation, intraoperative, and postoperative outcomes were reviewed and analyzed.

Results There were 12 men and 16 women. The mean age was $71.46 \pm 6.82$ years. Ten patients were in New York Heart Association class III or IV. The mean cardiopulmonary bypass and aortic cross-clamping times were $117.6 \pm 21.3$ and $98.1 \pm 22.6$ minutes, respectively. The mean time to extubation was $9.7 \pm 5.6$ hours, the mean intensive care unit stay was $37.4 \pm 14.6$ hours, and the mean hospital stay was $6.9 \pm 3.2$ days. There was one patient who underwent reoperation for bleeding. There were no instances of postoperative stroke, myocardial infarction, renal failure, or wound

Keywords

- minimally invasive surgery

- valve surgery

- CABG infection. The mean follow-up was $19 \pm 2.4$ months.

Conclusion Presence of RCA lesion is not a contraindication for minimally invasive approach in cases who underwent single or combined valve surgery. Combined valve surgery and right $C A B G$ via right anterior minithoracotomy are a safe and feasible option to standard median sternotomy surgery, even if RCA lesions seem suitable for stenting.
\end{abstract}

\section{Introduction}

Minimally invasive surgical interventions in cardiac surgery have been developed increasingly ever since it was first described in the later 1990s. ${ }^{1,2}$ The superiority of minimal invasive surgery as a lower morbidity, shorter hospital length of stay, and less blood transfusion requirement has been reported in many studies. ${ }^{3-6}$ Combined valve surgery and coronary artery bypass grafting (CABG) have been generally related to high risk of morbidity and mortality compared received

March 19, 2021

accepted after revision

May 4, 2021
DOI https://doi.org/

10.1055/s-0041-1731284.

ISSN 0171-6425.

\footnotetext{
(C) 2022. The Author(s).

This is an open access article published by Thieme under the terms of the Creative Commons Attribution-NonDerivative-NonCommercial-License, permitting copying and reproduction so long as the original work is given appropriate credit. Contents may not be used for commercial purposes, or adapted, remixed, transformed or built upon. (https://creativecommons.org/ licenses/by-nc-nd/4.0/) Georg Thieme Verlag KG, Rüdigerstraße 14, 70469 Stuttgart, Germany
} 
with isolated valve surgery or CABG and it is performed by conventional median sternotomy in many centers. ${ }^{7,8}$ Furthermore, hybrid procedures in which percutaneous coronary intervention $(\mathrm{PCI})$ are performed for critical coronary artery disease followed by minimally invasive valve surgery have provided a safe and effective option for patients with concomitant valvular and coronary artery disease, which generally have been a contraindication to minimally invasive surgery. ${ }^{9-11}$

Cases with combined valve and coronary artery disease, which are not proper for a hybrid procedure, are commonly performed by standard median sternotomy approach for CABG and valve surgery. In this study, we aimed to define our experiences and clarify the safety and feasibility of a minimally invasive approach to combined valve pathology and single-vessel right coronary artery (RCA) disease in all level regardless of suitability for PCI.

\section{Materials and Methods}

\section{Study Design}

This retrospective study included 28 consecutive patients who underwent minimally invasive concomitant single or combined valve surgery and right CABG between February 2018 and December 2020. All operations were performed by the same surgical team. Patients with a history of previous cardiac surgery and multivessel coronary artery disease were excluded.

The study protocol was approved by the institutional Ethics Committee of Ankara University. Our research was conducted in accordance with the principles of the Declaration of Helsinki. A written informed consent was obtained from each patient.

\section{Preoperative Evaluation}

Preoperatively transthoracic echocardiography, coronary angiography, and thoracic computed tomography without contrast were performed for all patients. In asymptomatic patients with critical RCA lesion and/or unsuitable for stenting, low molecular weight heparin and vasodilators were used until surgery. In symptomatic patients, coronary artery stenting was applied, valve surgery was postponed for 3 or 4 weeks, and this population was excluded.

\section{Surgical Technique}

All patients were prepared in supine position with a pressure bag inflated under the right scapula to elevate the right hemithorax. This allows better exposure through intercostal spaces. External defibrillation pads were placed and standard monitoring including electrocardiogram, near infrared spectroscopy, and blood pressure was applied. After the induction of anesthesia, double-lumen selective tracheal intubation was performed to allow single lung ventilation for all patients. Intraoperative transesophageal echocardiographic (TEE) evaluation was performed routinely.

A cut-down procedure was performed at the level of groin, then femoral artery and vein were exposed. Cardiopulmonary bypass (CPB) was conducted with femoral artery can- nulation and bicaval venous cannulation via femoral vein and internal jugular vein. $15 \mathrm{~F}$ to $21 \mathrm{~F}$ arterial cannula (Biomedicus, Medtronic, Minneapolis, Minnesota, United States) was used for femoral artery cannulation, $21 \mathrm{~F}$ to $25 \mathrm{~F}$ venous cannula was used for femoral vein cannulation, and $15 \mathrm{~F}$ to 19F cannula was used for percutaneously internal jugular vein cannulation. Seldinger technique was applied to cannulate each vessel. The position of venous cannulas was confirmed by using TEE through a bicaval view. The induction of $\mathrm{CPB}$ and the greater saphenous vein harvesting were performed simultaneously.

Thereafter, a 5 to $6 \mathrm{~cm}$ skin incision was positioned in the 3rd or 4th intercostal space. To provide better exposure for all heart valves, the lower intercostal space was used via the same skin incision. ${ }^{12}$ A surgical skin incision was applied starting from the point of 4 to 10 hours around the lower border of the inferior nipple-areolar complex in the right breast in patients with isolated mitral and tricuspid valvular disease. In patients undergoing aortic valve surgery, we performed incision from third intercostal space from midclavicular point to just $2 \mathrm{~cm}$ lateral of sternum. A soft tissue retractor and small rib spreader were placed, respectively. After the CPB was initiated, the pericardium was opened and tacked to the skin with 5 or 6 sutures. A Chitwood clamp (Scanlan International, Inc, St. Paul, Minnesota, United States) was placed in the anterior midaxillary line in the two or right third interspace and advanced into the transverse sinus. The antegrade cardioplegia cannula was inserted at the ascending aorta. The aorta was clamped and CustodiolHTK (Essential Pharmaceuticals, Durham, North Carolina, United States) cardioplegia was infused for myocardial protection. Moderate hypothermia was performed for all cases. A carbon dioxide $\left(\mathrm{CO}_{2}\right)$ diffuser was placed in the pericardial cavity.

After the diastolic cardiac arrest was achieved, first of all, RCA bypass graft was anastomosed. Coronary anastomosis was applied with standard instruments. To gain excellent exposure for the crux of RCA, deep traction silk sutures were placed on the pericardium and the heart was decompressed with vacuum assist. This approach was not useful for the posterior descending artery (PDA) or the posterolateral artery. The patient was placed in the advanced Trendelenburg position before PDA bypass grafting, so diaphragmatic surface of heart was getting close to surgical area. Additionally, few silastic traction sutures lying parallel to PDA were put at $1 \mathrm{~cm}$ proximal and distal portion of the target lesion. These sutures were pulled caudally to expand the vision for better anastomosis (-Fig. 1). A retracting elastic suture passed around RCA and the sling sutures were placed on the crux of heart and retracted to expose distal RCA. This approach provides great exposure of the vessels. ${ }^{9,13}$ Greater saphenous vein was prepared and coronary anastomosis was performed with conventional technique using 7-0 Prolene (Ethicon, Somerville, New Jersey, United States) suture (-Fig. 1).

After coronary revascularization, the valve surgery procedure was performed using long-shafted minimally invasive instruments (Geister, Tuttlingen, Germany). In patients who 


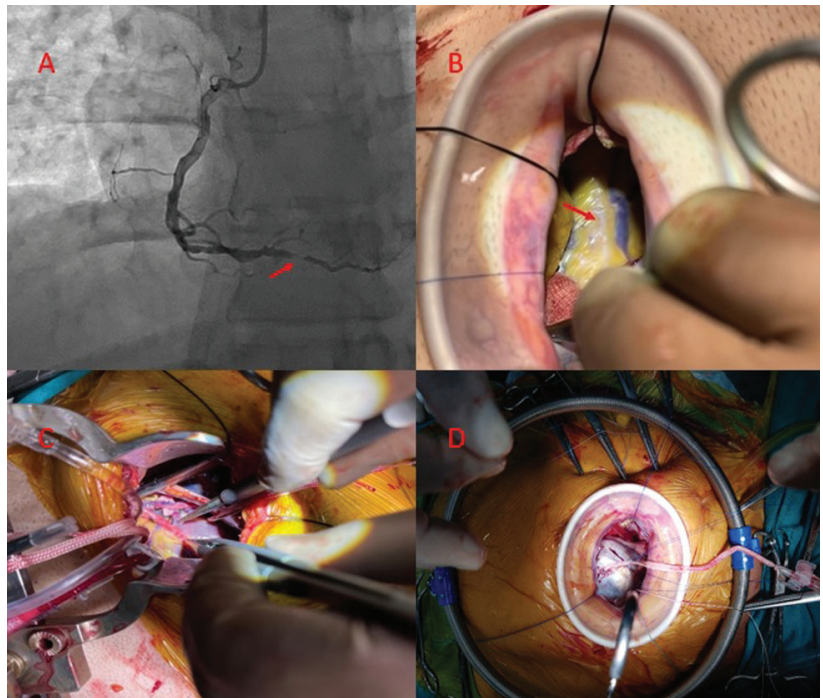

Fig. 1 (A) Coronary angiography diagram of posterior descending artery (PDA) lesion. (B) Exposure of PDA lesion. (C) Anastomosis of PDA lesion. (D) Anastomosis of proximal right coronary artery lesion.

underwent multivalve surgery, the lower intercostal space was used from the same skin incision to increase exposure. The left atriotomy was performed and a flexible suction for venting was placed into left atrium. Transverse aortotomy was applied $\sim 3.0$ to $3.5 \mathrm{~cm}$ above the aortic annulus; aortic valve was resected and decalcificated completely. Thereafter, mitral valve repair or replacement was performed with standard technique. The left atriotomy was closed with 4-0 Prolene (Ethicon, Somerville, New Jersey, United States) suture. Following that, the right atrium was opened and tricuspid ring annuloplasty was performed with Contour three-dimensional annuloplasty ring (Medtronic, Minneapolis, Minnesota, United States). After the right atrium was closed with 4-0 Prolene (Ethicon, Somerville, New Jersey, United States) suture, aortic valve was sized using Perceval-S (LivaNova, Saluggia, Italy) sizers. Intercommissural 4-0 Polypropylene sutures were placed to shrink annulus for changing elliptical shape into circular one. Thereafter, 4-0 Polypropylene guiding sutures passed through at the three commissures to avoid mispositioning of guiding sutures after the additional interventions into annulus. The collapsed Perceval (LivaNova, Saluggia, Italy) valve was delivered using its dedicated holder using the three guiding sutures and deployed at the level of aortic annulus after maintaining circular annulus. The delivery system and the three guiding sutures were then removed. ${ }^{14}$ Aortotomy was closed using 3-0 Prolene (Ethicon, Somerville, New Jersey, United States) suture. Proximal vein graft anastomosis was performed in an end-to-side fashion to ascending aorta using 6-0 Prolene (Ethicon, Somerville, New Jersey, United States) suture. Following the end of surgical procedure, before aortic declamping, a ventricular pacing wire was positioned on the diaphragmatic surface of the right-ventricular and a chest drain tube was inserted from right costa-diaphragmatic recess through outside. Pacing wire was pinned to chest drain and pulled out together and stabilized. Then aortic cross clamping was removed.

\section{Statistical Analysis}

Data was collected using the Statistical Package for the Social Sciences (SPSS) version 25.0 software (SPSS Inc, Chicago, Illinois, United States). Continuous variables were presented in mean \pm standard deviation (SD) or median (min-max). Categorical variables were expressed in numbers and percentages.

\section{Results}

\section{Patients Characteristics}

Demographic data and medical history details of study population are presented in - Table 1. A total of 28 patients were identified and 16 patients $(57.1 \%)$ of them were women. The mean age was $71.4 \pm 6.8$ years and mean logistic

Table 1 Patients' baseline characteristics

\begin{tabular}{|l|l|}
\hline Variable & \\
\hline$n$ & 28 \\
\hline Age, mean \pm SD, years & $71.46 \pm 6.82$ \\
\hline Female, $n$ (\%) & $16(57.1 \%)$ \\
\hline Body mass index, kg/m ${ }^{2}$, mean \pm SD & $27.13 \pm 2.07$ \\
\hline Logistic EuroSCORE II, mean \pm SD (\%) & $6.21 \pm 2.57$ \\
\hline Ejection fraction, mean \pm SD (\%) & $54.72 \pm 8.12$ \\
\hline PASP (mm Hg) & $41.4 \pm 8.3$ \\
\hline New York Heart Association functional class & \\
\hline$\bullet$ I-II & $18(64.3 \%)$ \\
\hline$\bullet$ III-IV & $10(35.7 \%)$ \\
\hline Previous myocardial infarction, $n(\%)$ & $2(7.1 \%)$ \\
\hline Hypertension, $n$ (\%) & $15(53.6 \%)$ \\
\hline Diabetes mellitus, $n(\%)$ & $9(32.1 \%)$ \\
\hline Dyslipidemia, $n$ (\%) & $16(57.1 \%)$ \\
\hline Preoperative creatinine, mean \pm SD, mg/dL & $0.95 \pm 0.27$ \\
\hline Chronic obstructive lung disease, $n(\%)$ & $6(21.4 \%)$ \\
\hline Previous stroke, $n$ (\%) & $1(3.6 \%)$ \\
\hline Peripheral vascular disease, $n(\%)$ & $4(14.2 \%)$ \\
\hline Atrial fibrillation & $5(17.9 \%)$ \\
\hline Aortic valve pathology & $14(50 \%)$ \\
\hline$\bullet$ Isolated stenosis, $n(\%)$ & $11(39.3 \%)$ \\
\hline$\bullet$ Mixed, $n(\%)$ & $3(10.7 \%)$ \\
\hline Mitral valve pathology & $23(82.1 \%)$ \\
\hline$\bullet$ Isolated stenosis, $n(\%)$ & $10(35.7 \%)$ \\
\hline$\bullet$ Isolated regurgitation, $n(\%)$ & $8(28.6 \%)$ \\
\hline$\bullet$ Mixed, $n(\%)$ & $5(17.9 \%)$ \\
\hline Tricuspid regurgitation, $n(\%)$ & $7 \%)$ \\
\hline
\end{tabular}

Abbreviations: PASP, pulmonary artery systolic pressure; SD, standard deviation.

Data presented as $n(\%)$ or mean \pm SD. 
Single or Combined Valve Surgery and Concomitant RCA Bypass through Right Anterior Minithoracotomy Approach Hasde et al.

EuroScore was $6.2 \pm 2.6$. Ten patients (35.7\%) were in New York Heart Association functional class III or IV, mean left ventricle ejection fraction was $54.7 \pm 8.2$, mean systolic pulmonary arterial pressure was $41.4 \pm 8.3 \mathrm{~mm} \mathrm{Hg}$, and preoperative creatinine was $0.95 \pm 0.27 \mathrm{mg} / \mathrm{dL}$. Three patients had atrial fibrillation.

The indication for aortic valve replacement (AVR) was aortic stenosis in 11 and mixed aortic valve disease in 3 patients. The indication for mitral valve replacement (MVR) or mitral ring annuloplasty was mitral stenosis in 10, mitral regurgitation in 8 , and mixed mitral valve disease was in 5 patients. In seven patients, the indication for tricuspid ring annuloplasty was tricuspid regurgitation.

\section{Operative Outcomes}

Surgical procedures are presented in -Table 2. The mean (SD) CPB and aortic cross-clamping times were 117.6 (21.3) and 98.1 (22.6) minutes, respectively. Cryoablation for atrial fibrillation was performed for five patients (17.9\%).

Multiple valve surgery was performed with concomitant RCA bypass in 14 patients (two valve surgery for 13 patients and three valve surgery for one patient).

Surgical exposure was successfully obtained in all patients, and none needed conversion to median sternotomy.

\section{Postoperative Outcomes}

Postoperative outcomes are detailed in - Table 3. There was no hospital mortality and mortality at 30 days. The mean (SD) time to extubation was 9.7 (5.6) hours, the mean (SD) intensive care unit stay was 37.4 (14.6) hours, and the mean (SD) hospital stay was 6.9 (3.2) days. There was one patient who underwent reoperation for bleeding. One patient who performed cryoablation had postoperative atrial fibrillation.

Table 2 Intraoperative outcomes

\begin{tabular}{|c|c|}
\hline Variables & \\
\hline $\begin{array}{l}\text { Cardiopulmonary bypass } \\
\text { time (min), mean } \pm \text { SD }\end{array}$ & $117.64 \pm 21.33$ \\
\hline $\begin{array}{l}\text { Aortic cross clamping } \\
\text { time (min), mean } \pm S D\end{array}$ & $98.11 \pm 22.63$ \\
\hline Cryoablation & $5(17.9 \%)$ \\
\hline \multicolumn{2}{|l|}{$\begin{array}{l}\text { Surgical procedures combined } \\
\text { to RCA bypass grafting }\end{array}$} \\
\hline - AVR, n (\%) & $6(21.4 \%)$ \\
\hline - $\mathrm{AVR}+\mathrm{MRA}, n(\%)$ & $2(7.1 \%)$ \\
\hline - AVR + MVR, $n(\%)$ & $5(17.9 \%)$ \\
\hline - $\mathrm{AVR}+\mathrm{MRA}+\mathrm{TRA}, n(\%)$ & $1(3.6 \%)$ \\
\hline - MVR, $n(\%)$ & 7 (25\%) \\
\hline - MRA, $n(\%)$ & $2(7.1 \%)$ \\
\hline - MRA + TRA, $n(\%)$ & $2(7.1 \%)$ \\
\hline - MVR + TRA, $n(\%)$ & $4(14.3 \%)$ \\
\hline
\end{tabular}

Abbreviations: AVR, aortic valve replacement; MRA, mitral ring annuloplasty; MVR, mitral valve replacement; RCA, right coronary artery; SD, standard deviation; TRA, tricuspid ring annuloplasty.

Data are presented as $n(\%)$ or mean \pm SD.
Table 3 Postoperative outcomes

\begin{tabular}{|c|c|}
\hline Variables & \\
\hline \multicolumn{2}{|l|}{ Clinical outcomes } \\
\hline - Time to extubation, mean $\pm S D, h$ & $9.7 \pm 5.6$ \\
\hline - ICU stay, mean \pm SD, h & $37.4 \pm 14.6$ \\
\hline - Hospital stay, mean \pm SD, d & $6.9 \pm 3.2$ \\
\hline \multicolumn{2}{|l|}{ Echocardiographic outcomes } \\
\hline Aortic valve & $n=14$ \\
\hline - Presence of PVL, $n(\%)$ & $1(7.1 \%)$ \\
\hline - $\mathrm{PVL} \leq 1, n(\%)$ & $1(7.1 \%)$ \\
\hline - $\mathrm{PVL} \geq 1, n(\%)$ & $0(0 \%)$ \\
\hline - Mean gradient $(\mathrm{mm} \mathrm{Hg})$ & $11.6 \pm 1.8$ \\
\hline Mitral valve & $n=23$ \\
\hline - Mild regurgitation, $n(\%)$ & $2(8.7 \%)$ \\
\hline - Moderate regurgitation, $n(\%)$ & $0(0 \%)$ \\
\hline - Severe regurgitation, n (\%) & $0(0 \%)$ \\
\hline - Mean gradient (mm Hg) & $4.1 \pm 1.2$ \\
\hline \multicolumn{2}{|l|}{ Morbidity and mortality } \\
\hline - Reoperation for bleeding, $n(\%)$ & $1(3.6 \%)$ \\
\hline - Stroke, $n(\%)$ & $0(0 \%)$ \\
\hline - Myocardial infarction, $n(\%)$ & $0(0 \%)$ \\
\hline - Renal failure, n (\%) & $0(0 \%)$ \\
\hline - Atrial fibrillation, $n(\%)$ & $1(3.6 \%)$ \\
\hline $\begin{array}{l}\text { - Temporary pace-maker } \\
\text { requirement, } n(\%)\end{array}$ & $3(10.7 \%)$ \\
\hline $\begin{array}{l}\text { - Permanant pace-maker } \\
\text { requirement, } n(\%)\end{array}$ & $0(0 \%)$ \\
\hline - Wound infection, $n$ (\%) & $0(0 \%)$ \\
\hline - Hospital mortality, n (\%) & $0(0 \%)$ \\
\hline - 30-day mortality, n (\%) & $0(0 \%)$ \\
\hline
\end{tabular}

Abbreviations: ICU, intensive care unit; PVL, paravalvular leak; SD, standard deviation.

Data are presented as $n(\%)$ or mean \pm SD.

There were no instances of postoperative stroke, myocardial infarction, renal failure, or wound infection.

The postoperative echocardiographic evaluation is shown in -Table 3. The mean postoperative aortic valve gradient was $11.6 \pm 1.8 \mathrm{~mm} \mathrm{Hg}$. The mean mitral transvalvular gradient was $4.1 \pm 1.2 \mathrm{~mm} \mathrm{Hg}$. There was no structural valve deterioration, migration of the prosthesis, thrombus formation, endocarditis, or malpositioning detected at follow-up.

\section{Follow-Up}

The patients followed for $19 \pm 2.4$ months, transthoracic echocardiography at discharge and 3, 6, and 12 months postoperatively and annually thereafter, a complete physical examination, electrocardiography registration, chest radiography, and blood samples were performed for all patients. 


\section{Discussion}

Combined valve surgery and CABG have been associated with worse outcomes than isolated valve surgery or isolated CABG. ${ }^{11}$ There has also been evidence that combined valve surgery and $C A B G$ result in increased postoperative mortality, with some studies showing a twofold increase in mortality from 4.1 to $4.4 \%$ with isolated AVR or MVR and 8.9 to $9.8 \%$ with concomitant CABG although some assessments reported a greater than additive risk of major morbidity and mortality as high as $22 \%{ }^{15}$

In concurrent minimally invasive valve surgery and CABG, less invasive approaches such as hybrid procedures have been identified to enhance outcomes of this combination. Byrne et al first described this hybrid approach in $2005 .{ }^{16}$ In this retrospective study, 26 patients underwent $\mathrm{PCI}$ followed by minimally valve surgery within a median of 5 days. The operative mortality was $3.8 \%$, which was much lower than the predictive mortality of $22 \%$. However, due to the use of dual antiplatelet therapy, a high incidence of bleeding was seen and blood transfusion was required for $85 \%$ of study patients. To avoid bleeding and blood transfusion, Brinster et al applied the PCI on the day of or the evening before the planned minimally invasive AVR to evade the antiplatelet effect of the drugs during surgery. ${ }^{10}$ In eight patients, blood transfusion was required and there were no reoperations because of bleeding. Santana et al reported that hybrid approach is associated with less bleeding and blood transfusion requirement, lower morbidity, shorter intensive care unit, and hospital length of stay when compared with median sternotomy. ${ }^{11}$

In our study population, if there were no critical RCA lesions and/or hemodynamic instability, PCI was not performed to RCA even if suitable for stenting. We assume that right anterior minithoracotomy provides excellent exposure for right CABG. In some studies, safety and feasibility of right anterior minithoracotomy approach for combined valve surgery and right CABG were shown. Lamelas et al reported feasibility and safety of right anterior minithoracotomy approach for concomitant valve surgery and CABG. Seventeen patients who underwent AVR and CABG through right anterior minithoracotomy were evaluated. There was one reoperation for bleeding and there were no postoperative myocardial infarctions. There was no hospital mortality and all patients were alive at a mean follow-up of 2 years. ${ }^{9}$ In our series, there were patients who had multiple valve disease and RCA lesions ranging from proximal to distal end. Furthermore, Lamelas et al performed rib resection from costochondral junction to improve the exposure that may lead more postoperative pain. We did not need any rib resection.

In the literature, less invasive surgery approaches for concomitant valve surgery and CABG are quite limited. Smit et al reported on 12 patients who underwent combined minimally invasive valve surgery and CABG via bilateral minithoracotomies. ${ }^{17}$ In this study, combined procedures were compared with 104 conventional sternotomy and there was no difference between the groups in postoperative morbidity. In addition, none of the minimally invasive procedures required conversion to sternotomy.

According to our study, presence of RCA lesion is not contraindication for minimally invasive approach in cases who underwent single or combined valve surgery. Our results have shown that concomitant single or combined valve surgery and right CABG via right anterior minithoracotomy are a safe, effective, and less invasive option to standard median sternotomy surgery in patients with RCA lesions even if suitable for stenting.

\section{Study Limitations}

Limitations of the present study are single center and retrospective study design. Another limitation of this study is the lack of control group receiving conventional combined valve pathology and single-vessel RCA substitutes. Therefore, we planned a large prospective, randomized, controlled trial comparing minimally invasive versus conventional approach to combined valve pathology and single-vessel RCA disease.

\section{Conflict of Interest}

None.

\section{References}

1 Murzi M, Cerillo AG, Bevilacqua S, Gilmanov D, Farneti P, Glauber M. Traversing the learning curve in minimally invasive heart valve surgery: a cumulative analysis of an individual surgeon's experience with a right minithoracotomy approach for aortic valve replacement. Eur J Cardiothorac Surg 2012;41(06): 1242-1246

2 Raja SG, Navaratnarajah M. Impact of minimal access valve surgery on clinical outcomes: current best available evidence. J Card Surg 2009;24(01):73-79

3 Cohn LH, Adams DH, Couper GS, et al. Minimally invasive cardiac valve surgery improves patient satisfaction while reducing costs of cardiac valve replacement and repair. Ann Surg 1997;226(04): 421-426, discussion 427-428

4 Navia JL, Cosgrove DM III. Minimally invasive mitral valve operations. Ann Thorac Surg 1996;62(05):1542-1544

5 Schmitto JD, Mokashi SA, Cohn LH. Minimally-invasive valve surgery. J Am Coll Cardiol 2010;56(06):455-462

6 Lamelas J, Sarria A, Santana O, Pineda AM, Lamas GA. Outcomes of minimally invasive valve surgery versus median sternotomy in patients age 75 years or greater. Ann Thorac Surg 2011;91(01): 79-84

7 Wang L, Li B, Liu C, Rong T, Yu Y, Gu C. Short- and medium-term effects of combined mitral valve surgery and coronary artery bypass grafting versus coronary artery bypass grafting alone for patients with moderate ischemic mitral regurgitation: a metaanalysis. J Cardiothorac Vasc Anesth 2016;30(06):1578-1586

8 Seipelt RG, Schoendube FA, Vazquez-Jimenez JF, Doerge H, Voss M, Messmer BJ. Combined mitral valve and coronary artery surgery: ischemic versus non-ischemic mitral valve disease. Eur J Cardiothorac Surg 2001;20(02):270-275

9 Mihos CG, Santana O, Pineda AM, La Pietra A, Lamelas J. Aortic valve replacement and concomitant right coronary artery bypass grafting performed via a right minithoracotomy approach. Innovations (Phila) 2014;9(04):302-305

10 Brinster DR, Byrne M, Rogers CD, et al. Effectiveness of same day percutaneous coronary intervention followed by minimally invasive aortic valve replacement for aortic stenosis and moderate coronary disease ("hybrid approach"). Am J Cardiol 2006;98(11): 1501-1503 
11 Santana O, Funk M, Zamora C, Escolar E, Lamas GA, Lamelas J. Staged percutaneous coronary intervention and minimally invasive valve surgery: results of a hybrid approach to concomitant coronary and valvular disease. J Thorac Cardiovasc Surg 2012;144 (03):634-639

12 Gumus F, Hasde AI, Bermede O, Kilickap M, Durdu MS. Multiple valve implantation through a minimal invasive approach: comparison of standard median sternotomy and right anterior thoracotomy. Heart Lung Circ 2020;29(09): 1418-1423

13 Lewis CT, Stephens RL, Cline JL, Tyndal CM. Concurrent minimally invasive aortic valve replacement and coronary artery bypass via limited right anterior thoracotomy. Innovations (Phila) 2015;10 (04):273-275
14 Baran C, Durdu MS, Gumus F, et al. Sutureless aortic valve replacement with concomitant valvular surgery. J Thorac Cardiovasc Surg 2018;155(06):2414-2422

15 Cao D, Chiarito M, Pagnotta P, Reimers B, Stefanini GG. Coronary revascularization in transcatheter aortic valve implantation candidates: why, who, when? Interv Cardiol 2018;13(02):69-76

16 Byrne JG, Leacche M, Unic D, et al. Staged initial percutaneous coronary intervention followed by valve surgery ("hybrid approach") for patients with complex coronary and valve disease. J Am Coll Cardiol 2005;45(01):14-18

17 Smit PJ, Shariff MA, Nabagiez JP, Khan MA, Sadel SM, McGinn JT Jr. Experience with a minimally invasive approach to combined valve surgery and coronary artery bypass grafting through bilateral thoracotomies. Heart Surg Forum 2013;16(03):E125-E131 